\title{
The Use of Solvation Models in Gas Chromatography
}

\author{
Fabrice Mutelet
}

Additional information is available at the end of the chapter

http://dx.doi.org/10.5772/48381

\section{Introduction}

Gas chromatography is widely used for determining thermodynamic properties of pure substances or solvent properties of binary mixtures. From retention data, the solute activity coefficient at infinite dilution, the gas-liquid partition coefficient and others thermodynamic properties of mixing can be easily obtained. Using these parameters and appropriate models allows understanding of the intermolecular interactions responsible for solvation in the stationary phase [1-2]. The solvation parameter model is now well established as a useful tool for obtaining quantitative structure-property relationships for chemical, biomedical and environmental processes. The model correlates a free-energy related property of a system to six free-energy derived descriptors describing molecular properties. The ultimate goal is to establish a suitable quantitative structure-property relationship (QSPR) to facilitate the prediction of further system properties for compounds lacking experimental values. Two broad strategies are generally employed in QSPR studies. The first approach is based on theoretical descriptors. The advantage of using the QSPR approach based on theoretical descriptors is that all of the necessary parameters for prediction can be calculated purely from the three-dimensional representation of the molecular structure of each of the compounds of the mixtures, including mixtures of chemically diverse compounds [3-4]. The main weakness of this approach is that the selected descriptors may be difficult to understand and the models may lack obvious chemical significance. The second approach is based on descriptors determined using experimental technique such as gas chromatography.

In this review, we will present the different possibility of using chromatographic methods to facilitate the rapid and convenient measurement of the LSER model presentsed in reference [5]. An application of the LSER model on ionic liquids will be presented. The last paragraph will be focused on the use of the LSER model coupled to a group contribution model for the estimation of the partition coefficient of organic compounds in ionic liquids. 


\section{Solvation models used in gas chromatography}

\subsection{Linear solvation energy relationship}

In numerous solvation models, the partition of a solute between the gas phase and a solvent (or stationary phase) may be described by a cavity theory of solution [6-7] in which the solvation process is divided into three steps. In the step 1, a cavity of suitable size to accommodate the solute is created in the solvent. This process is endoergic because work is required to disrupt solvent-solvent interactions. In the second step, the solvent molecules around the cavity are reorganized from their original positions to the positions they will adopt when the solute is in equilibrium with the solvent. Of course, these positions are not fixed but are averages of solvent positions. The Gibbs energy change for such reorganization is assumed to be negligible, by analogy with the melting of a solid. However, enthalpy and entropy changes in reorganizations may be large, again by analogy with the melting of a solid. In the last step, the solute is introduced into the reorganized cavity, and various solute-solvent interactions are set up, all of which are exoergic.

Several thermodynamic properties are related to partitioning between water and other phases, for example octanol (Kow) or the pure compound itself (water solubility). These partitioning processes can be understood from thermodynamic concepts-like free energy, chemical potential and fugacity. The equilibrium partition constant between two phases, on a mole fraction basis, can be expressed as:

$$
\mathrm{K}_{\mathrm{i} 12}=\exp \left(-\Delta_{12} \mathrm{G}_{\mathrm{i}} / \mathrm{RT}\right)
$$

where $\Delta_{12} G_{i}$ is the Gibbs energy (or free energy) of transfer between the two phases, $R$ is the general gas constant and $\mathrm{T}$ is the absolute temperature. The Gibbs energy sums up both the enthalpic $\left(\Delta_{12} \mathrm{H}\right)$ and entropic $\left(\Delta_{12} \mathrm{~S}\right)$ effects resulting from changes in intermolecular interactions:

$$
\Delta_{12} \mathrm{G}_{\mathrm{i}}=\Delta_{12} \mathrm{H}_{\mathrm{i}}-\mathrm{T} \Delta_{12} \mathrm{~S}_{\mathrm{i}}
$$

The calculation of partitioning from structural or other descriptors therefore requires the modelling of these effects. The Gibbs energy change can also be separated into the contributions of van der Waals and polar interactions, assuming that these are additive:

$$
\Delta_{12} G_{i}=\Delta_{12} G_{i}^{v d W}+\Delta_{12} G_{i}^{p o l a r}
$$

In the early 1980's, Taft \& Kamlet [8-12] have developed the basic concept of linear solvation energy relationships (LSERs). They have demonstrated for thousands of chemical systems that some property which is linearly related to either a free energy of reaction, a free energy of transfer, or an activation energy can be correlated with various fundamental molecular properties of the solvents or solutes involved. Chromatographic retention and in particular logarithmic retention factors $\left(\log k^{\prime}\right)$, logarithmic partition coefficients $\left(\log K_{\mathrm{L}}\right)$ are linear free energy parameters and as such one can linearly correlate these data with the molecular properties of the solutes using the LSER model [13-16]. 

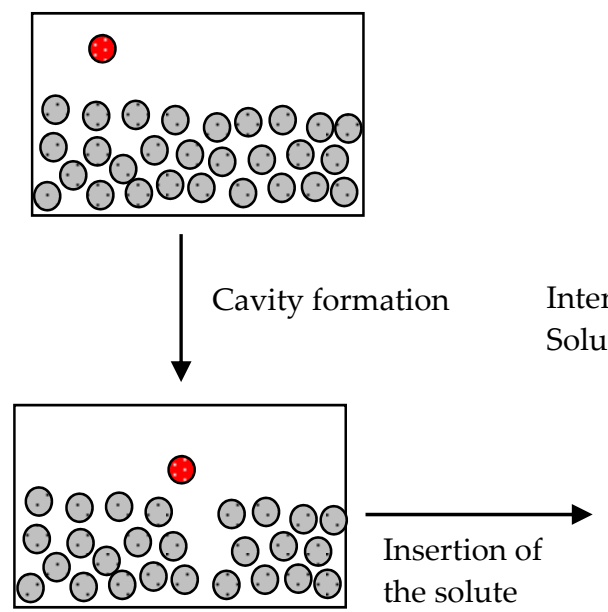

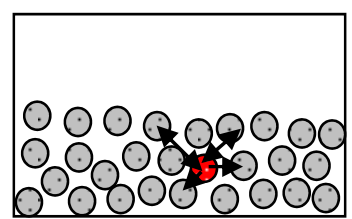

teractions Solute-Solvant

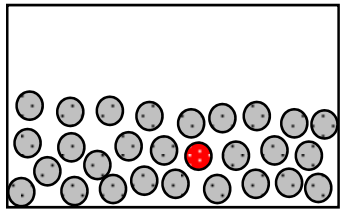

Figure 1. Model of the solvation process.

The most recent representation of the LSER model proposed by Abraham and coworkers [5, 17-19] is given by equation (4)

$$
\log \mathrm{P}=\mathrm{c}+\mathrm{r} \cdot \mathrm{R}_{2}+\mathrm{s} \cdot \Pi_{2}^{\mathrm{H}}+\mathrm{a} \cdot \sum \mathrm{a}_{2}^{\mathrm{H}}+\mathrm{b} \cdot \sum \beta_{2}^{\mathrm{H}}+1 \cdot \log \mathrm{L}^{16}
$$

Where SP is a solvation parameter related with the free energy change such as gas-liquid partition coefficient, specific retention volume or adjusted retention time at a given temperature. The capital letters represent the solutes properties and the lower case letters the complementary properties of the stationary phase. The solute descriptors are the excess molar refraction $\mathrm{R}_{2}$, dipolarity/ polarizability $\pi_{2}^{H}$, hydrogen bond acidity basicity, $\Sigma \alpha_{2}^{H}$ and $\sum \beta_{2}^{H}$, respectively, and the gas-liquid partition coefficient on n-hexadecane at $298 \mathrm{~K}$, $\log \mathrm{L}^{16}$. The solute descriptors may be determined using inverse gas chromatography or estimated using a group contribution method. A databank of descriptors for about 3000 compounds may be found in the literature $[2,20,21]$. The coefficients $c, e, s, a, b$ and $l$ are not simply fitting coefficients, but they reflect complementary properties of the solvent phase. These coefficients are determined by mutiple linear regression of equation (4). This model was strongly applied to characterize chemicals products, petroleum fluids.

\subsection{Determination of LSER parameters of pure solutes}

\subsubsection{Determination of $\log L^{16}$}

To preserve the general character of equation (4), all characteristic parameters should be carefully determined and correlation between parameters should be avoided. Experimental procedures of successive determination of LSER parameters were described in the literature [20, 22-24]. Log $\mathrm{L}^{16}$ characterizes the most general interactions present in every physical system and should be determined before other parameters [24]. The original values of log 
$\mathrm{L}^{16}$ were determined from retention data of organic compounds on n-hexadecane coated packed columns at $298.2 \mathrm{~K}$ [5]. A number of papers proposed techniques based on the use of either capillary or packed columns in wide temperature ranges and replacing the nhexadecane with other non-polar stationary phases. The gas liquid partition coefficient of a solute is directly related to the experimental capacity factor, $\mathrm{k}$, by equation:

$$
\mathrm{L}=\mathrm{k} \frac{\mathrm{V}_{\mathrm{M}}}{\mathrm{V}_{\mathrm{S}}}=\frac{\mathrm{k}}{\Phi}
$$

where $V_{M}$ and $V_{S}$ are the volumes of the mobile and stationary phases, respectively, and $\Phi$ is the phase ratio $\left(V_{S} / V_{M}\right)$. Experimental determination of $\log L^{16}$ is often very difficult. Adsorption phenomena introduce an important error in determination of the capacity factor. Zhang et al. [23] determined $\log \mathrm{L}^{16}$ with capillary columns coated with n-hexadecane and concluded that results were not influenced by adsorption in this case. However, recent results presented in reference [25] showed that this improvement is not general and that an interfacial adsorption still exists with capillary columns. Moreover, it is very difficult to obtain absolute retention data using this technique. Li et al. [24] and Abraham et al. [25] studied influence of the solute support and of the stationary phase loading on adsorption phenomena. They concluded that the high loading ratio (up to $20 \%$ ) of the stationary phase and the high temperature of the column allow to reduce adsorption. In this case, the knowledge of $\mathrm{R}_{2}, \sum \alpha_{2}^{H}$ and $\pi_{2}^{H}$ parameters is necessary. The number and the nature of parameters needed for calculation depend on the stationary phase used.

Serious difficulties arise when $\log \mathrm{L}^{16}$ of non-volatile compounds is to be measured. This is due to the definition of $\log \mathrm{L}^{16}$ itself. Indeed, direct experimental determination of $\log \mathrm{L}^{16}$ of compounds less volatile than n-hexadecane is impossible. In the case of heavy compounds slightly more volatile than n-hexadecane the experiment is possible but difficult, especially at $298.2 \mathrm{~K}$. Often it is recommended to measure retention times at higher temperatures and then extrapolate partition coefficients to the ambient temperature. In this case, the quality of results depends strongly on the extrapolation method used. The problem of the temperature dependence of retention times was often discussed in literature. A suitable extrapolation procedure was described in reference [26]. In the case of compounds less volatile than nhexadecane several authors proposed to work with columns coated with long chain branched paraffins and to establish relationships between corresponding partition coefficients and $\log \mathrm{L}^{16}[16,26]$. Defayes et al. [26] worked with apolane coated stationary phase (apolane is a $\mathrm{C}_{87} \mathrm{H}_{176}$ branched alkane). This column can be used at temperatures up to $550 \mathrm{~K}$ without a weight loss of the stationary phase. Moreover, it was shown that the effect of adsorption at the liquid-gas interface is negligible in this case [26]. However, this opinion is not generally accepted and Werckwerth et al. [16] found the influence of adsorption in the case of strongly polar compounds. The same authors observed that a linear relationship exists between gas-apolane partition coefficients, $\log \mathrm{L}^{87}$ and $\log \mathrm{L}^{16}$ and that the data obtained with apolane can be used to estimate the value of $\log \mathrm{L}^{16}$. Moreover, they demonstrated that strong correlation between both partition coefficients exists also for log 
$\mathrm{L}^{87}$ determined at significantly higher temperature [16]. Recently, several authors investigated the use of predictive methods to estimate $\log L^{16}[27,28]$. This approach is particularly interesting to determine the $\log \mathrm{L}^{16}$ of nonvolatile compounds.

\subsubsection{Determination of $\log L^{16}$ using capillary columns}

A direct determination of the stationary phase mass is difficult in the case of capillary or Megabore columns and the use of relative methods to determine partition coefficient from retention data is often preferred. In this case, different approaches were proposed to calculate partition coefficient based on the well-established value of log Ln-hexane [23]. Corresponding equation is as follows:

$$
\mathrm{L}_{X}=\mathrm{L}_{\mathrm{n} \text {-hexane }} \frac{{ }_{\mathrm{R}, X}-\mathrm{t}_{\mathrm{m}}}{\mathrm{t}_{\mathrm{R}, \mathrm{n} \text {-hexane }}-\mathrm{t}_{\mathrm{m}}}
$$

where $t_{R}$ and $t_{m}$ are the solute retention time and the dead time of the column respectively. Retention data of the solute $X$ and of $n$-hexane should be determined at the same temperature. Available data of log Ln-hexane on apolane were determined at $312.4 \mathrm{~K}$ [16]. On the other hand, it was shown that partition coefficients determined at two temperatures are linearly correlated [16].

$$
\log \mathrm{L}_{\mathrm{T}}^{87}=\operatorname{alog} \mathrm{L}_{\mathrm{T}^{\prime}}^{16}+\mathrm{b}
$$

New relationship can be established between the partition coefficient of the solute $X$ at temperature $T$ and the partition coefficient of the n-hexane at temperature $T^{\prime}$. This relationship is based on the observation verified with several n-paraffin stationary phases that equation (7) for one stationary phase is reduced to the following form:

$$
\log \mathrm{L}_{\mathrm{T}}^{87}=\log \mathrm{L}_{\mathrm{T}^{\prime}}^{87}+\mathrm{b}
$$

Equations (6) and (8) lead to relationship between the partition coefficient at temperature $\mathrm{T}$ of the solute $X$ and the partition coefficient of n-hexane determined at temperature $T^{\prime}$ :

$$
\left(\mathrm{L}_{\mathrm{X}}\right)_{\mathrm{T}}=\left(\mathrm{L}_{\mathrm{n} \text {-hexane }}\right)_{\mathrm{T}} \times\left(\frac{{ }_{\mathrm{R}, \mathrm{X}}-\mathrm{t}_{\mathrm{m}}}{\mathrm{t}_{\mathrm{R}, \mathrm{n}-\text { hexane }}-\mathrm{t}_{\mathrm{m}}}\right)_{\mathrm{T}^{\prime}}
$$

Apolane coated capillary columns are considered as an appropriate tool to determine $\log \mathrm{L}^{16}$ of heavy compounds. Studies of Defayes et al. [26] and Werckwerth et al. [16] provided arguments supporting this opinion. As it can be seen in Table 1, results obtained with a similar but deactivated column are in good agreement with literature. Chromatographic peaks obtained with non-polar and polar compounds were symmetric. While this method gave good results at high temperatures, the column was deactivated irreversibly within few hours. A probable explanation of this phenomenon is that the adhesion between apolane 


\begin{tabular}{llllll}
\hline Compounds & $\log \mathrm{L}^{16 a}$ & $\log \mathrm{L}^{16 e x p}$ & Compounds & $\log \mathrm{L}^{16 \mathrm{a}}$ & $\log \mathrm{L}^{16 \mathrm{exp}}$ \\
\hline n-Hexane & 2.668 & 2.660 & Triethylamine & 3.040 & 2.947 \\
n-Octane & 3.677 & 3.670 & 1-Butanol & 2.539 & 2.545 \\
n-Nonane & 4.182 & 4.180 & 1-Pentanol & 3.106 & 3.094 \\
n-Decane & 4.685 & 4.686 & 1-Octanol & 4.569 & 4.556 \\
n-Undecane & 5.191 & 5.189 & 1-Decanol & 5.628 & 5.631 \\
n-Dodecane & 5.696 & 5.699 & Butanone & 2.287 & 2.274 \\
n-Tridecane & 6.200 & 6.198 & 2-Pentanone & 2.755 & 2.758 \\
n-Tetradecane & 6.705 & 6.701 & Pyridine & 3.022 & 3.033 \\
n-Pentadecane & 7.209 & 7.205 & Thiophene & 2.819 & 2.809 \\
n-Hexadecane & 7.714 & 7.711 & Naphthalene & 5.161 & 5.162 \\
Benzene & 2.792 & 2.810 & 1-Methyl naphthalene & 5.789 & 5.785 \\
Toluene & 3.325 & 3.331 & 2-Methyl naphthalene & 5.771 & 5.772 \\
Ethylbenzene & 3.778 & 3.782 & 1,4-Dimethylnaphthalene & 6.339 & 6.338 \\
o-Xylene & 3.939 & 3.943 & 1,6- Dimethylnaphthalene & 6.280 & 6.284 \\
m-Xylene & 3.868 & 3.870 & cis-Decahydronaphtalene & & 5.162 \\
p-Xylene & 3.839 & 3.841 & Indane & 4.590 & 4.598 \\
1,3,5-Trimethylbenzene & 4.344 & 4.348 & Phenanthrene & 7.632 & 7.638 \\
1,2-Diethylbenzene & 4.732 & 4.728 & & &
\end{tabular}

Table 1. Partition coefficient $\log \mathrm{L}^{16}$ exp. at $298.2 \mathrm{~K}$ obtained with a $\mathrm{C}_{50} \mathrm{H}_{102}$ packed column at $373.2 \mathrm{~K}$. $\log$ $\mathrm{L}^{16}$ a : data taken from $[5,14,21,31]$.

and the deactivated silica does not assure the film stability at higher temperature [24, 27]. Our experience indicates that the use of commercially available apolane coated capillary columns should be limited to low temperature ranges. In the case of heavy compounds this implies very long retention times and imposes injection of samples of important volume, which induces adsorption effects. Consequently, to determine $\log \mathrm{L}^{16}$ of heavy compounds we decided to use packed columns with long chain n-alkane stationary phase. Moreover, results obtained with a non-deactivated column indicate that retention times are influenced by adsorption phenomena. Indeed, polar solutes exhibited severely asymmetric peaks and their retention times strongly depended on the sample size. Retention times of alcohols are longer than the literature values that may indicate the presence of active sites.

\subsubsection{Determination of $\log L^{16}$ using packed columns}

Problems of the capillary column stability encouraged us to review the possibility of application of packed columns for determining $\log \mathrm{L}^{16}$ of non-volatile compounds. Stationary phases used were long chain n-alkanes, n-hexatriacontane and n-pentacontane. They were used at temperatures up to $320 \mathrm{~K}$ without significant loss of weight. The essential problem encountered with packed columns concerned adsorption effects [30, 23]. Mutelet \& Rogalski [2] used teflon columns, inert and stable up to $330 \mathrm{~K}$. Selecting an appropriate support material can reduce the adsorption on the surface of the support. Preliminary tests showed that the best results were obtained with the Chromosorb PAW DMCS and the 
Chromosorb WHP. Both supports were loaded with $25 \%$ of n-pentacontane. The fact that with Chromosorb PAW DMCS retention times depend on the sample size and chromatographic peaks are asymmetric indicates the presence of adsorption. Moreover, retention times of alcohols are longer than expected, indicating the presence of active adsorption sites on the support surface. The Chromosorb WHP support has a lower specific area and a smaller concentration of hydroxyl groups which reduces the adsorption. Results obtained are in good agreements with literature data for most of the compounds studied and retention times depend only slightly on the sample size. However, retention times observed with polyaromatic hydrocarbons are still longer than expected. Good results were obtained by deactivating the column (Table 1) with Silyl 8, as recommended by [31]. The use of packed columns with Chromosorb WHP coated with n-alkane and deactivated with Silyl 8 made it possible to obtain a homogenous set of $\log \mathrm{L}^{16}$ in good agreement with literature data.

\subsubsection{Determination of $\log L^{16}$ using temperature gradient method}

The packed column technique can be used to measure $\log \mathrm{L}^{16}$ data of volatile organic compounds. The reasonable limit of application of this method is the retention time of neicosane. Experimental difficulties make hazardous quantitative determination $\log \mathrm{L}^{16}$ of heavier compounds. To enlarge the applicability of chromatographic methods to organic compounds less volatile than n-eicosane, a method based on the temperature gradient chromatography can be used. Recently, Donovan [32] showed that retention times of heavy organic compounds obtained in a gradient mode are linearly related to the logarithm of the vapor pressure at $298.2 \mathrm{~K}$. The authors used a DB-1 megabore column at high flow rates of the gas phase. This method making it possible to reduce considerably retention time was applied to determine vapor pressures of pesticides and polyaromatic hydrocarbons. Nevertheless, the stationary phase DB-1 is slightly polar [24]. Corresponding system parameters of the poly(dimethylsiloxane) immobilized in DB-1 column were published in the reference [24]. Values determined at $\mathrm{t}=60^{\circ} \mathrm{C}$ are as follows: $\mathrm{r}=0, \mathrm{~s}=0.211, \mathrm{a}=0.308$ and $\mathrm{b}$ $=0$. Therefore, experimental results obtained with a DB-1 column can be used to determine $\log \mathrm{L}^{16}$ only if LSER parameters expressing solute polarity are known. No general relationship between the reduced retention time and $\log \mathrm{L}^{16}$ valid with all organic compounds can be obtained without the knowledge of above parameters.

However, this approach can be used to establish relationship between the reduced retention time and $\log \mathrm{L}^{16}$ within a series of compounds. Indeed, polar parameters vary only slightly and in a regular way within a series. Moreover, certain parameters decrease strongly with rising temperature [24]. Therefore, it can be supposed that the effect of the stationary phase polarity is nearly constant within a homologous series of moderately polar compounds. Measurements performed in a gradient mode with several homologous series confirmed this hypothesis. However, linear relationship does not afford the precision required for the $\log \mathrm{L}^{16}$ determination. It was noticed that not only the reduced retention time tr but also the corresponding temperature $\mathrm{T}$ is needed to establish the appropriate function. Function log $\mathrm{L}^{16}=\mathrm{f}(\mathrm{tr}, \mathrm{T})$ is linear with $\mathrm{R}=0.996$ that is not enough to represent the $\log \mathrm{L}^{16}$ with the precision required. We found that the suitable function is as follows: 


$$
\log \mathrm{L}^{16}=\exp \left(\frac{\mathrm{f}\left(\mathrm{t}_{\mathrm{R}}\right)}{\mathrm{T}}\right)
$$

In the case of $n$-alkanes, function $\mathrm{f}\left(\mathrm{t}_{\mathrm{R}}\right)$ was obtained with $\log \mathrm{L}^{16}$ literature data of $\mathrm{n}$-alkanes from n-dodecane up to $n$-docosane. The plot of $f\left(t_{R}\right)$ and values of parameters determining this function are given in Figure 1 . The $\log \mathrm{L}^{16}$ of $\mathrm{n}$-alkanes up to $\mathrm{n}=38$ calculated with equation (10) using gradient mode results are presented in Table 2. It is reasonable to suppose that partition coefficients of heavy n-alkanes up to approximately $\mathrm{C}_{45} \mathrm{H}_{92}$ can be obtained with gradient method. It should be pointed out that the present approach based on the gradient mode chromatography can be used only to determine log $\mathrm{L}^{16}$ within a homologous series of moderately polar compounds. The use of the present method with less polar stationary phase (recently, Li et al. [24] shown that in the case of SPB columns $r=0, a=$ $0, \mathrm{~b}=0)$ can facilitate the study of polar compounds and perhaps obtain more general results.

\begin{tabular}{llll}
\hline Compounds & $\mathrm{t} R$ & $\log \mathrm{L}^{16 \exp }$ & $\log \mathrm{L}^{16 \mathrm{a}, \mathrm{b}}$ \\
\hline n-Undecane & 3.70 & 5.221 & $5.191^{\mathrm{a}}$ \\
n-Dodecane & 5.87 & 5.705 & $5.696^{\mathrm{a}}$ \\
n-Tridecane & 8.18 & 6.195 & $6.200^{\mathrm{a}}$ \\
n-Tetradecane & 10.60 & 6.707 & $6.705^{\mathrm{a}}$ \\
n-Pentadecane & 12.98 & 7.221 & $7.209^{\mathrm{a}}$ \\
n-Hexadecane & 15.15 & 7.707 & $7.714^{\mathrm{a}}$ \\
n-Heptadecane & 17.42 & 8.237 & $8.218^{\mathrm{a}}$ \\
n-Octadecane & 19.47 & 8.739 & $8.722^{\mathrm{a}}$ \\
n-Nonadecane & 21.42 & 9.239 & $9.226^{\mathrm{a}}$ \\
n-Eicosane & 23.30 & 9.743 & $9.731^{\mathrm{a}}$ \\
n-heinecosane & 25.12 & 10.253 & $10.236^{\mathrm{a}}$ \\
n-Docosane & 26.85 & 10.760 & $10.740^{\mathrm{a}}$ \\
n-Tricosane & 28.48 & 11.259 & $11.252^{\mathrm{a}}$ \\
n-Tetracosane & 30.05 & 11.759 & $11.758^{\mathrm{a}}$ \\
n-Pentacosane & 31.57 & 12.262 & $12.244^{\mathrm{b}}$ \\
n-Hexacosane & 33.07 & 12.779 & $12.744^{\mathrm{b}}$ \\
n-Heptacosane & 34.47 & 13.280 & $13.244^{\mathrm{b}}$ \\
n-Octacosane & 35.82 & 13.780 & $13.744^{\mathrm{b}}$ \\
n-Nonacosane & 37.15 & 14.291 & $14.244^{\mathrm{b}}$ \\
n-Heinetriacontane & 39.70 & 15.321 & $15.244^{\mathrm{b}}$ \\
n-dotriacontane & 40.80 & 15.787 & $15.744^{\mathrm{b}}$ \\
n-Pentatriacontane & 44.00 & 17.223 & $17.244^{\mathrm{b}}$ \\
n-Hexatriacontane & 45.08 & 17.736 & $17.744^{\mathrm{b}}$ \\
n-Octatriacontane & 47.00 & 18.684 & $18.744^{\mathrm{b}}$ \\
\hline
\end{tabular}

Table 2. Retention times tr and partition coefficients $\log \mathrm{L}^{16} \exp$ of $\mathrm{n}$-alkanes determined at $298.2^{\circ} \mathrm{C}$ using the gradient method on DB-1 column. $\log \mathrm{L}^{16} \mathrm{a}, \mathrm{b}$ a: -literature data $[5,14,21,31]$. b: -estimates calculated using the group contribution method proposed by reference [2]. 


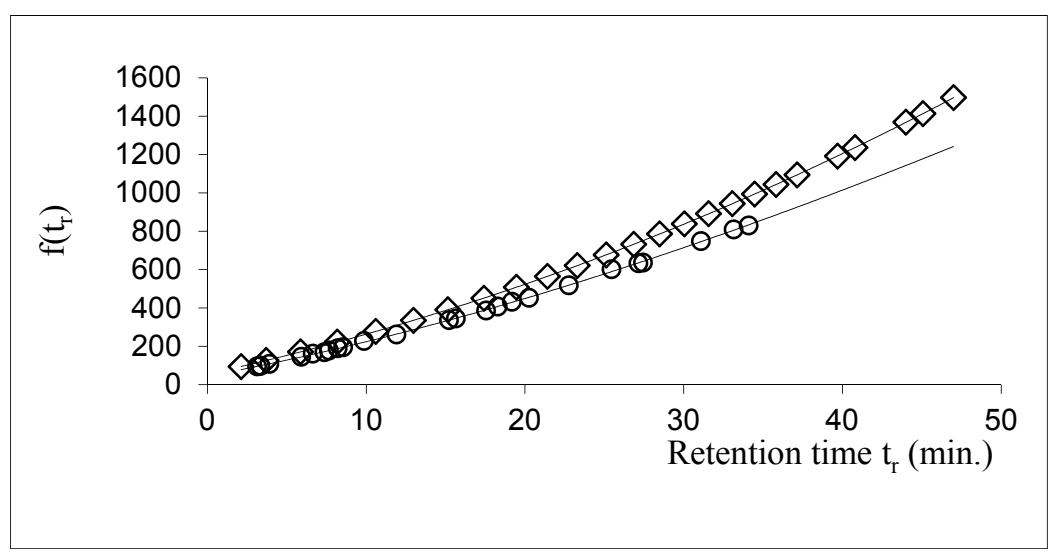

Figure 2. Plot of $\mathrm{f}(\mathrm{tr})$ function established with temperature gradient method; aromatics and polyaromatics $(0)$, n-alkanes $(\diamond)$.

\subsubsection{Determination of polar LSER parameters}

The excess molar refraction $\mathrm{E}$ is defined by the difference between the value for the solute molar refraction and the molar refraction for an alkane of the same characteristic volume:

$$
\mathrm{R}_{2}=M R_{X}(\text { solute })-M R_{X}\left(\text { alkane of the same } V_{X}\right)
$$

The solute molar refraction is calculated from the following equation:

$$
\mathrm{MR}_{X}=\frac{10 \cdot\left(\mathrm{n}^{2}-1\right) \cdot \mathrm{V}_{X}}{\left(\mathrm{n}^{2}+2\right)}
$$

Where $\mathrm{Vx}$ is the specific volume in $\mathrm{cm}^{3} \cdot \mathrm{mol}^{-1 / 100}$ and $\mathrm{n}$ the refractive index of the solute.

Abraham et al. [18] set out to construct scales of solute hydrogen bond acidity and hydrogen bond basicity using $\log \mathrm{K}$ values for reaction 1 in tetrachloromethane. The authors set out $\log \mathrm{K}$ values for a series of acids against 45 given bases. If $\log \mathrm{K}$ values for acids in a given reference base is plotted against log $\mathrm{K}$ values for acids in another reference base, a series of straight lines is observed with an intersection at a magic point of $-1.1 \mathrm{log}$ units. It is found that:

$$
\log \mathrm{K}(\text { series of acids against reference base } \mathrm{B})=\mathrm{L}_{\mathrm{B}} \log \mathrm{K}_{\mathrm{A}}^{\mathrm{H}}+\mathrm{D}_{\mathrm{B}}
$$

Where Lв and Dв characterize the base and $\log K_{A}^{H}$ values characterize the series of acids. The $\Sigma \alpha_{2}^{H}$ and $\Sigma \beta_{2}^{H}$ parameters are then defined by: 


$$
\begin{aligned}
& \sum \mathrm{a}_{2}^{\mathrm{H}}=\left(\log \mathrm{K}_{\mathrm{A}}^{\mathrm{H}}+1.1\right) / 4.636 \\
& \sum \beta_{2}^{\mathrm{H}}=\left(\log \mathrm{K}_{\mathrm{B}}^{\mathrm{H}}+1.1\right) / 4.636
\end{aligned}
$$

The $\sum \alpha_{2}^{H}$ and $\sum \beta_{2}^{H}$ parameters can be determined at the same time with $\pi_{2}^{H}$ parameter. Retention data (such as retention volume, partition coefficients) of the solute in three stationary phases at least of different polarity can be used to determine the $\Sigma \alpha_{2}^{H}, \Sigma \beta_{2}^{H}$ and $\pi_{2}^{H}$. Each stationary phase can be described by equation (16):

$$
\log K_{L}=c+r \cdot R_{2}+s \cdot \Pi_{2}^{H}+a \cdot \sum a_{2}^{H}+b \cdot \sum \beta_{2}^{H}+1 \cdot \log L^{16}
$$

At first, the LSER parameters c, s, a, b and 1 of each stationary phase are determined by multiple linear regression using solutes for which $R_{2}, \sum \alpha_{2}^{H}, \sum \beta_{2}^{H}, \pi_{2}^{H}$ and $\log \mathrm{L}^{16}$ are known. Then, $\sum \alpha_{2}^{H}, \sum \beta_{2}^{H}, \pi_{2}^{H}$ can be determined by multiple linear regression.

\subsubsection{Group contribution Method for calculation of LSER parameters of organic compounds}

Predictive methods allow to calculate these physico-chemical parameters which are inacessible via direct experiment. This alternative is particularly interesting in the case of log $\mathrm{L}^{16}$ of nonvolatile compounds. We consider that experimental methods described in the preceeding paragraph are useful for determination of LSER parameters of volatile and moderatly non-volatile compounds. Therefore, the large data bank of log $\mathrm{L}^{16}$ values already available in the literature can be used to establish group additivity rules and to predict log $\mathrm{L}^{16}$ of less volatile compounds. Havelec \& Sevcik [27,28] presented a general group contribution method making it possible to calculate accurate estimates of $\log \mathrm{L}^{16}$ of about 2000 organic compounds. The number of groups necessary to obtain good estimates of log $\mathrm{L}^{16}$ depends on the complexity of the molecular structure and rises in the case of polyfunctional molecules. This explains a high number of adjustable parameters used in the model $[27,28]$. For instance, $\log \mathrm{L}^{16}$ of non-aromatic hydrocarbons is established with 33 parameters and 9 structural contributions. The total number of all group parameters, interactional parameters and structural contributions is of 131 . The contribution of a given group is represented in the reference $[27,28]$ with three parameters related to the structure of the molecule and to its interactions with the stationary phase. As $\log \mathrm{L}^{16}$ is dependent on the solute vapor pressure and on the infinite dilution activity coefficient this approach is basically correct. However, molecular interactions are always related to n-hexadecane and certain parameters can be correlated. Platts et al. [20] recently proposed a new predictive method based on a careful analysis of contributions of various functional groups to establish $\log \mathrm{L}^{16}$ and other LSER parameters. Therefore, molecular segments were defined in view to obtain good estimates of each. The $\log \mathrm{L}^{16}$ of hydrocarbons is calculated with 9 parameters 
only. This method was established with 81 parameters, using a databank of 1908 compounds. A new model was proposed to calculating $\log \mathrm{L}^{16}$ for nonvolatile organic compounds with special attention paid to heavy hydrocarbons. Data for 550 organic compounds containing mainly hydrocarbons and members of homologous series were used in regression. Basic heteroatom segments were taken into account but the polyfunctional organic compounds were not dealt with. Values of $\log \mathrm{L}^{16}$ were taken from literature $[5,21]$. To elaborate the group contribution method a simple and efficient approach was used. Accordingly, $\log \mathrm{L}^{16}$ of the compounds $\mathrm{X}$ was calculated with the following expression:

$$
\log L_{x}^{16}=\sum_{i} n_{i} \cdot c_{i}
$$

where $\mathrm{C}_{\mathrm{i}}$ is the contribution of the group " $\mathrm{i}$ " and ni is the number of groups " $\mathrm{i}$ " in the compound X.

Platts et al. [20] have developed and tested additive models for six important molecular LFER descriptors, namely, $\mathrm{R}_{2}, \sum \alpha_{2}^{H}, \sum \beta_{2}^{H}, \pi_{2}^{H}$ and $\log \mathrm{L}^{16}$. Five of these six, all bar $\sum \alpha_{2}^{H}$

are calculated from a single set of 81 atom and group fragments, while $\sum \beta_{2}^{H}$ is calculated from a separate set of 51 fragments. In general, the linear fit obtained with these additive models is good, with $\mathrm{R}_{2}$ and $\log \mathrm{L}^{16}$ in particular giving excellent correlation. Splitting the data into training and test sets has also tested the predictive ability of such models, and is found to be almost as accurate as the full regressions. The performance of the method in calculating descriptors for "difficult" structures, ones containing intramolecular interactions such as hydrogen bonds, has been analyzed. Variations in descriptors due to such interactions are generally found to be reproduced, though inevitably some small discrepancies are found. In conclusion, this model is particurlarly powerful and useful for the prediction of LSER parameters of heavy and complicated molecules.

\section{Application of linear solvation energy relationship on ionic liquids}

The LSER model may be used to characterize the stationary phases in chromatography. In this case, a large number of solutes (between 20 and 50) for which LSER parameters $\mathrm{R}_{2}$, $\sum \alpha_{2}^{H}, \sum \beta_{2}^{H}, \pi_{2}^{H}$ and $\log L^{16}$ are known have to be injected. The LSER parameters characterizing the stationary phases (c, s, r, a, b and l) are determined by multiple linear regression. In the literature, there is a large amount of data of partition coefficients or activity coefficients measured by gas-liquid chromatography or by dilutor technique. Some system constants for various ionic liquids and classical solvents at $25^{\circ} \mathrm{C}$ are summarized in Table 3. The data for the 1-ethanol-3-methylimidazolium tetrafluoroborate, 1-ethanol-3methylimidazolium hexafluorophosphate, 1,3-dimethylimidazolium dimethylphosphate and 1-ethyl-3-methylimidazolium diethylphosphate [33], 1-Butyl-3-methylimidazolium tetrafluoroborate [34], n-Acryloyloxypropyl-N-methylimidazolium bromide and nMethacryloyloxyhexyl-N-methylimidazolium bromide [35], 1-Propenyl-3-alkyl-imidazolium 
bromide [36], 1-butyl-3-methylimidazolium octyl sulfate and 1-ethyl-3-methylimidazolium tosylate [37], Triethylsulphonium bis(trifluoromethylsulfonyl)imide [38], 1-Methyl-3ethylimidazolium bis(trifluorosulfonyl)-amide and 1.2-Dimethyl-3-ethylimidazolium bis(trifluorosulfonyl)-amide [39] were taken from the sources indicated. Poole \& Poole [40] found that the system constants of LSER model for the room temperature ionic liquids fall into the range $e=-0.62$ to $0.86, s=1.7-2.8, a=2.1-7.3, b=0-1.07$, and $l=0.35-0.96$. Compared with the scale of the polar organic solvents $e=-0.60$ to $0.82, s=0.54-2.8, a=0.28-5.50, b=0$ 4.8 , and $l=-0.21$ to 0.98 , we can see that both scales are similar indicating that the solvation properties for the room temperature ionic liquids are classical and fit quite well into the scales developed for polar molecular solvents.

The $(c+1 L)$ term gives information on the effect of cohesion of the ionic liquids on solute transfer from the gas phase. In general, the ionic liquids are cohesive solvents; they interact weakly via nonbonding and $\pi$-electrons ( $r$ system constant is zero) and are not much different to other polar non-ionic liquids. The ionic liquids are roughly as dipolar/polarizable as classical solvents. The hydrogen-bond basicity of the ionic liquid ( $a$ system constants) are considerably larger than values obtained for non phases (0-2.1) [1]. The hydrogen-bond basicity of Ils depends on the anion grafted on the cation. ionic liquids can be slightly more hydrogen-bond basic than dimethyl sulfoxide and $\mathrm{N}$ methylpyrrolidinone, and are weak to moderate hydrogen-bond acids, similar to the aliphatic alcohols. From Table 3 and data collected in the reference [40], we can see that the hydrogen-bond acidity of the ionic liquids depends largely on the cation and is lower for the 1,3-dialkylimidazolium salts with an alkyl group at C-2 position than 1,3dialkylimidazolium salts.

\section{Predictive models based on LSER model coupled to a group contribution method}

Solvation model may be also used to set up correlation between thermodynamic properties and LSER parameters. Abraham et al. [41,42] reported mathematical correlations based on the general Abraham solvation parameter model for the gas-to-solvent, $K_{L}$, and water-tosolvent, $P$, partition coefficients. Recently, [43-46] modified the Abraham solvation parameter model:

$$
\begin{aligned}
\log K_{L}= & \mathrm{c}_{\text {cation }}+\mathrm{c}_{\text {anion }}+\left(\mathrm{e}_{\text {cation }}+\mathrm{e}_{\text {anion }}\right) \cdot \mathbf{E}+\left(\mathrm{s}_{\text {cation }}+\mathrm{s}_{\text {anion }}\right) \cdot \mathbf{S}+ \\
& +\left(\mathrm{a}_{\text {cation }}+\mathrm{a}_{\text {anion }}\right) \cdot \mathbf{A}+\left(\mathrm{b}_{\text {cation }}+\mathrm{b}_{\text {anion }}\right) \cdot \mathbf{B}+\left(\mathrm{l}_{\text {cation }}+\mathrm{l}_{\text {anion }}\right) \cdot \mathbf{L} \\
\log P= & \mathrm{c}_{\text {cation }}^{\prime}+\mathrm{c}_{\text {anion }}^{\prime}+\left(\mathrm{e}_{\text {cation }}^{\prime}+\mathrm{e}_{\text {anion }}^{\prime}\right) \cdot \mathbf{E}+\left(\mathrm{s}^{\prime}{ }_{\text {cation }}+\mathrm{s}_{\text {anion }}^{\prime}\right) \cdot \mathbf{S} \\
& +\left(\mathrm{a}_{\text {cation }}^{\prime}+\mathrm{a}_{\text {anion }}^{\prime}\right) \cdot \mathbf{A}+\left(\mathrm{b}_{\text {cation }}+\mathrm{b}_{\text {anion }}^{\prime}\right) \cdot \mathbf{B}+\left(\mathrm{v}_{\text {cation }}+\mathrm{v}_{\text {anion }}\right) \cdot \mathbf{V}
\end{aligned}
$$

by rewriting each of the six solvent equation coefficients as a summation of their respective cation and anion contribution. The dependent variables in equations (18) and (19) are solutes descriptors as follows: $\mathbf{E}$ and $\mathbf{S}$ refer to the excess molar refraction in units of $\left(\mathrm{cm}^{3} \cdot \mathrm{mol}^{-1}\right) / 10$ and dipolarity/polarizability descriptors of the solute, respectively, $\mathbf{A}$ and $\mathbf{B}$ 


\begin{tabular}{|c|c|c|c|c|c|c|}
\hline \multirow[t]{2}{*}{ Ionic liquids and classical solvents } & \multicolumn{6}{|c|}{ System constants } \\
\hline & e & $\mathrm{s}$ & a & $\mathrm{b}$ & 1 & c \\
\hline $\begin{array}{l}\text { 1-ethanol-3-methylimidazolium } \\
\text { hexafluorophosphate }\end{array}$ & 0 & 3.03 & 2.89 & 1.13 & 0.47 & -1.14 \\
\hline $\begin{array}{l}\text { 1-ethanol-3-methylimidazolium } \\
\text { tetrafluoroborate }\end{array}$ & 0 & 3.03 & 3.64 & 0.763 & 0.5 & -1.35 \\
\hline $\begin{array}{l}\text { 1,3-dimethylimidazolium } \\
\text { dimethylphosphate }\end{array}$ & 0.86 & 2.59 & 7.27 & 0 & 0.35 & -0.61 \\
\hline $\begin{array}{l}\text { 1-ethyl-3-methylimidazolium } \\
\text { diethylphosphate }\end{array}$ & 0.26 & 1.97 & 6.9 & 0 & 0.54 & -0.09 \\
\hline $\begin{array}{l}\text { 1-Butyl-3-methylimidazolium } \\
\text { tetrafluoroborate }\end{array}$ & 0.56 & 2.82 & 3.27 & 0.48 & 0.5 & -0.77 \\
\hline $\begin{array}{l}\text { n-Acryloyloxypropyl-N-methylimidazolium } \\
\text { bromide }\end{array}$ & 0 & 2.88 & 5.5 & 0 & 0.48 & -1.03 \\
\hline $\begin{array}{l}\text { n-Methacryloyloxyhexyl-N- } \\
\text { methylimidazolium bromide }\end{array}$ & 0 & 2.46 & 5.36 & 0 & 0.57 & -0.87 \\
\hline 1-Propenyl-3-methyl-imidazolium bromide & 0 & 2.16 & 5.19 & 0 & 0.53 & -1.86 \\
\hline 1-Propenyl-3-octyl-imidazolium bromide & 0 & 1.72 & 4.96 & 0 & 0.57 & -1.6 \\
\hline 1-Propenyl-3-decyl-imidazolium bromide & 0 & 1.73 & 4.89 & 0 & 0.66 & -1.58 \\
\hline 1-Propenyl-3-dodecyl-imidazolium bromide & 0 & 1.44 & 4.87 & 0 & 0.72 & -1.51 \\
\hline 1-Butyl-3-methylimidazolium octyl sulfate & 0 & 1.47 & 4.05 & 0 & 0.68 & -0.237 \\
\hline 1-Ethyl-3-methylimidazolium tosylate & 0.54 & 2.4 & 4.81 & 0.17 & 0.48 & -0.84 \\
\hline n-Butylammonium thiocyanate & 0.14 & 1.65 & 2.76 & 1.32 & 0.45 & -0.75 \\
\hline $\begin{array}{l}\text { 1-Methyl-3-ethylimidazolium } \\
\text { bis(trifluorosulfonyl)-amide }\end{array}$ & 0.148 & 2.277 & 2.172 & 1.041 & 0.629 & -0.439 \\
\hline $\begin{array}{l}\text { 1.2-Dimethyl-3-ethylimidazolium } \\
\text { bis(trifluorosulfonyl)-amide }\end{array}$ & 0.214 & 2.347 & 2.075 & 0.896 & 0.655 & -0.565 \\
\hline $\begin{array}{l}\text { Triethylsulphonium } \\
\text { bis(trifluoromethylsulfonyl)imide }\end{array}$ & 0.114 & 2.37 & 2.34 & 0.696 & 0.642 & -0.803 \\
\hline $\begin{array}{l}\text { 1-Ethyl-3-methylimidazolium } \\
\text { Trifluoroacetate }\end{array}$ & 0.608 & 1.63 & 4.21 & 1.81 & 0.584 & -0.918 \\
\hline $\begin{array}{l}\text { 1-Butyl-3-methylimidazolium } \\
\text { Trifluoromethanesulfonate }\end{array}$ & 0.399 & 2.03 & 3.49 & 0.681 & 0.647 & -0.784 \\
\hline Trifluoroethanol & -0.547 & 1.339 & 2.213 & 3.807 & 0.645 & -0.092 \\
\hline Methanol & -0.22 & 1.17 & 3.7 & 1.43 & 0.769 & -1.27 \\
\hline Water & 0.82 & 2.74 & 3.9 & 4.81 & -0.213 & 0 \\
\hline 1.2 Dichoroethane & -0.47 & 1.676 & 0.92 & 0.486 & 0.927 & 0.025 \\
\hline Dry methyl acetate & -0.447 & 1.675 & 2.625 & 0.213 & 0.874 & 0.129 \\
\hline Dry ethyl acetate & -0.352 & 1.316 & 2.891 & 0 & 0.916 & 0.182 \\
\hline Ethylene glycol & 0.217 & 1.427 & 4.474 & 2.687 & 0.568 & -0.898 \\
\hline Benzene & -0.313 & 1.053 & 0.457 & 0.169 & 1.02 & 0.107 \\
\hline 2-(Cyclohexylamino)ethanesulfonate & 0.07 & 1.57 & 3.67 & 0 & 0.51 & -0.83 \\
\hline
\end{tabular}

Table 3. LSER descriptors of ionic liquids determined at $313.15 \mathrm{~K}$. 
are measures of the solute hydrogen-bond acidity and basicity, $\mathbf{V}$ is the McGowan volume in units of $\left(\mathrm{cm}^{3} \cdot \mathrm{mol}^{-1}\right) / 100$ and $\mathbf{L}$ is the logarithm of the gas-to-hexadecane partition coefficient at $298 \mathrm{~K}$. Sprunger et al. calculated equation coefficients for 8 cations and 4 anions using a database that contained 584 experimental $\log K_{L}$ and 571 experimental $\log P$ values. No loss in predictive accuracy was observed by separating the equation coefficients into individual cation-specific and anion-specific values. The major advantage of splitting the equation coefficients into individual cation-specific and anion-specific contributions is that one can make predictions for more ILs. In Sprunger's approach, the major advantage of splitting the equation coefficients into individual cation-specific and anion-specific contributions is that one can make predictions for more Ils. Most of the cations are alkylimidazolium. The use of this model is somewhat limited since it can not be extrapolated to alkylimidazolium ionic liquids not initially defined by the method (e.g. with long alkyl chains).

In the development of Mutelet et al. [47], the cation with its alkyl chains is splitted in

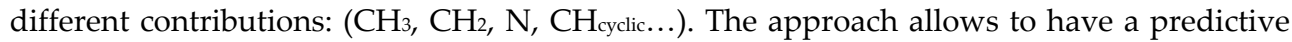
model. The aim of this work was to develop a group contribution method allowing to estimate the $\log K_{L}$ and $\log P$ of organic compounds in ionic liquids at $298 \mathrm{~K}$. Using the LSER model proposed by Abraham, the group contribution method expresses LSER coefficients $c_{i}, e_{i}, S_{i}, a_{i}, b_{i}$ and $l_{i}$ of equation (19). or $c_{i}^{\prime}, e_{i}^{\prime}, s_{i}^{\prime}, a_{i}^{\prime}, b_{i}^{\prime}$ and $v_{i}$ of equation (20) by:

$$
\begin{aligned}
& \log K_{L}=\sum_{i}^{21} n_{i} \times c_{i}+\sum_{i}^{21} n_{i} \times e_{i} \cdot \mathbf{E}+\sum_{i}^{21} n_{i} \times s_{i} \cdot \mathbf{S}+\sum_{i}^{21} n_{i} \times a_{i} \cdot \mathbf{A}+\sum_{i}^{21} n_{i} \times b_{i} \cdot \mathbf{B}+\sum_{i}^{21} n_{i} \times l_{i} \cdot \mathbf{L} \\
& \log P=\sum_{i}^{21} n_{i} \times c_{i}^{\prime}+\sum_{i}^{21} n_{i} \times e_{i}^{\prime} \cdot \mathbf{E}+\sum_{i}^{21} n_{i} \times s_{i}^{\prime} \cdot \mathbf{S}+\sum_{i}^{21} n_{i} \times a_{i}^{\prime} \cdot \mathbf{A}+\sum_{i}^{21} n_{i} \times b_{i}^{\prime} \cdot \mathbf{B}+\sum_{i}^{21} n_{i} \times v_{i} \cdot \mathbf{V}
\end{aligned}
$$

Where $\mathrm{n}_{\mathrm{i}}$ is the number of group i present in the ionic liquid.

Mutelet et al. [47] proposed to extend the temperature dependent GC-LSER in view of determining the partition coefficient of organic compounds in ionic liquids. The GC-LSER can be rewriting as followed:

$$
\log K_{L}=\text { const }+\frac{\sum_{i}^{21} n_{i} \times c_{i}+\sum_{i}^{21} n_{i} \times e_{i} \cdot E+\sum_{i}^{21} n_{i} \times a_{i} \cdot A+\sum_{i}^{21} n_{i} \times b_{i} \cdot B+\sum_{i}^{21} n_{i} \times l_{i} \cdot L}{T}
$$

The experimental data used to calculate Abraham's model ion-specific equation coefficients were taken from the collection of [43-46] and were updated with recent data. A total of 1450 gas-liquid partition coefficients and 1410 water-to-liquid partition coefficients were used for the calculation. Solutes were mainly n-alkanes, cycloalkanes, alkenes, alkynes, aromatics, alcohols, ethers, aldehydes, ketones, chloroalkanes. The $E$-scale varies from 0 to 1.5 , the $S$ scale from 0 to 1.72 , the $A$-scale from 0 to 1.04, the $B$-scale from 0 to 1.28 , the $L$-scale from 1.200 to 7.833 and the $V$-scale from 0.109 to 1.799 . The dataset is composed of 27 
imidazolium based ionic liquids, 3 ammonium, 3 pyridinium and 4 pyrolidinium based ionic liquids. The authors also add sulphonium and phosphonium ionic liquids although only one set of $K_{L}$ (or $P$ ) data may be found for these families. The twenty one groups which are defined in this method are listed in Table 4. The decomposition into groups of the ionic liquids is very easy, that is as simple as possible. No substitution effects are considered. No exceptions are defined. In Figure 3 are represented all ionic liquids studied in this work. Five groups are defined to describe the chains $\mathrm{R}_{1}, \mathrm{R}_{2}, \mathrm{R}_{3}$ and $\mathrm{R}_{4}$ grafted on the cation: $\mathrm{CH}_{3}$, $\mathrm{CH}_{2}$, -O-, - $\mathrm{O}-\mathrm{N}_{\mathrm{cycl}}$ and $-\mathrm{OH}$. These groups allow the calculation of partition coefficients of alkyl based ionic liquids but also functionalized ionic liquids such as ether, alcohols. The remaining seven groups are: $\mathrm{CH}_{2 \text { cyclic, }} \mathrm{CH}_{\text {cyclic, }} \mathrm{C}_{\text {cyclic, }} \mathrm{N}_{\text {cyclic, }} \mathrm{N}^{+}$(ammonium cation), $\mathrm{P}^{+}$ (phosphonium cation) and $\mathrm{S}^{+}$(sulphonium cation).

More precisely, $\mathrm{N}_{\text {cyclic }}$ represents two structures: $-\mathrm{N}^{+}=$and $-\mathrm{N}-$. Nine groups are used for anions: bis(trifluoromethylsulfonyl)imide $:(\mathrm{TF})_{2} \mathrm{~N}^{-}$, hexafluorophosphate: $\mathrm{PF}_{6}^{-}$, tetrafluoroborate: $\mathrm{BF}_{4}^{-}$, ethylsulfate: $\mathrm{EtSO}_{4}^{-}$, octylsulfate: $\mathrm{OcSO}_{4}^{-}$, thiocyanate: $\mathrm{SCN}^{-}$, trifluoromethylsulfonate : $\mathrm{CF}_{3} \mathrm{SO}_{3}^{-}$, trifluoroacetate : $\mathrm{ACF}_{3}^{-}$and dicyanamide: $(\mathrm{CN})_{2} \mathrm{~N}^{-}$. As an example, let's have a look at the decomposition of 1-butyl-3-methylimidazolium hexafluorophosphate. In this case, the decomposition of the molecule into elementary groups is: 2 group $1\left(-\mathrm{CH}_{3}\right)+3$ group $2\left(-\mathrm{CH}_{2}\right)+3$ group $7(\mathrm{C}$ cyclic $)+2$ group $9\left(\mathrm{~N}_{\text {cyclic }}\right)+1$ group $14\left(\mathrm{PF}_{6}\right)$.

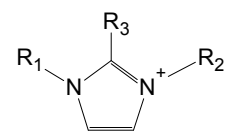

Imidazolium<smiles>[R][N+]([R])([R])[R]</smiles>

Ammonium<smiles>[R2]C1CC[N+]([R1])CC1</smiles>

Pyridinium<smiles>[R][P+]([R])([R])[R]</smiles>

Phosphonium

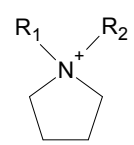

Pyrolidinium

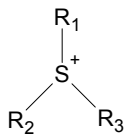

Sulphonium

Figure 3. Cation of six families of ionic liquids.

Group contribution model coupled to LSER (GC-LSER) for estimating the gas-to-ionic liquids partition coefficients and water-to-ionic liquids partition coefficients allows to predict with good accuracy $\log K_{L}$ and $\log P$ at $298 \mathrm{~K}$ of not only alkyl based ionic liquids but also functionalized ionic liquids. The parameters of the group contribution methods were determined for imidazolium, pyridinium, pyrrolidinium, phosphonium, ammonium and sulphonium based ionic liquids containing several different anions. A comparison between the experimental and calculated values showed that the proposed models describe 
the experimental data available with a mean absolute error of about $0.15 \log$ unit. While the model is probably somewhat limited in prediction for pyridinium and pyrrolidinium based ionic liquids because of the poor dataset for these cations, results obtained are satisfactory.

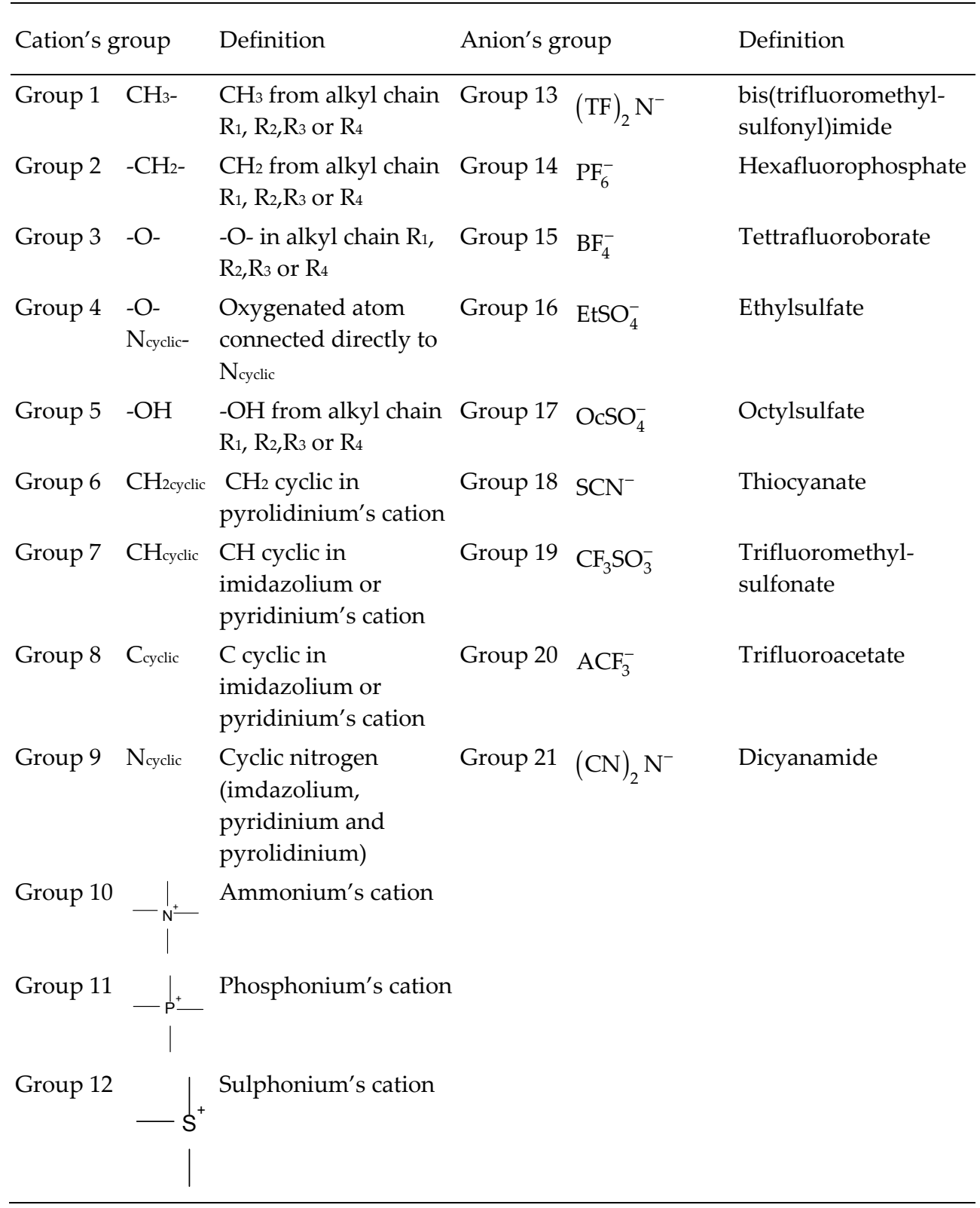

Table 4. Description of the 21 groups used for the estimation of $\log K_{L}$ and $\log P$. 


\section{Conclusion}

The solvation parameter model is suitable for describing the retention properties of molecules in chromatographic systems. To establish the system properties requires identification of a group of compounds with well known descriptor values. We have shown that all LSER parameters of solutes may be determined using gas chromatography or experimental techniques. The solvation model may be used either for the physico-chemical characterization of the stationary phases or for the establishment of a suitable quantitative structure-property relationship to facilitate the prediction of further system properties for compounds lacking experimental values.

\section{Author details}

Fabrice Mutelet

Laboratoire Réactions et Génie des Procédés (CNRS, UPR 3349), Ecole Nationale Supérieure des Industries Chimiques, Nancy CEDEX, France

\section{References}

[1] Poole, C.F. Chromatographic and spectroscopic methods for the determination of solvent properties of room temperature ionic liquids. Journal of Chromatography A 2004; 1037 49-82.

[2] Mutelet, F. \& Rogalski, M. Experimental determination and prediction of the gas-liquid n-hexadecane partition coefficients J. Chromatogr. A 2001; 923 153-163.

[3] Russom, C.L.; Breton, R.L.; Walker, J.D.; Bradury, S.P. An overview of the use of quantitative structure-activity relationships for ranking and prioritizing large chemical inventories for environmental risk assessments Environ. Toxicol. Chem. 2003; 22 18101821.

[4] Katritzky, A.R.; Maran, U.; Lobonov, V.S.; Karelson, M. Structurally Diverse Quantitative Structure-Property Relationship Correlations of Technologically Relevant Physical Properties J. Chem. Inf. Comput. Sci. 2000; 40 1-18.

[5] Abraham, M. H.; Grellier, P. L. \& Mc Gill R.A. Determination of Olive Oil-Gas and Hexadecane-Gas Partition Coefficients, and calculation of the corresponding Olive OilWater and Hexadecane-Water Partition Coefficients. J. Chem. Soc. PERKIN TRANS II 1987; 797-803.

[6] Vitha, M. \& Carr, P.W. (2006). The chemical interpretation and practice of linear solvation energy relationships in chromatography. Journal of Chromatography A 2006; 1126 143-194.

[7] Abraham, M.H., Poole, C.F. \& Poole, S.K. Classification of stationary phases and other materials by gas chromatography Journal of Chromatography A, 1999; 842 79-114.

[8] Kamlet, M.J.; Abboud, J.L. \& Taft, R.W. (1977). The solvatochromic comparison method. 6. The $\pi$ scale of solvent polarities. Journal of the American Chemical Society 1977; 18 (99) 6027-6038. 
[9] Kamlet, M.J.; Abboud, J.-L.M.; Abraham, M.H. \& Taft, R.W. Linear solvation energy relationships. 23. A comprehensive collection of the solvatochromic parameters, $\pi^{*}, \alpha$, and $\beta$, and some methods for simplifying the generalized solvatochromic equation. Journal of Organic Chemistry 1983; 17 (48) 2877-2887.

[10] Kamlet, M.J. \& Taft, R.W. Linear Solvation Energy Relationships. Local Empirical Rules -- or Fundamental Laws of Chemistry? A Reply to the Chemometricians., Acta Chem. Scand., B 1985; 39 611-628.

[11] Kamlet, M.J.; Doherty, R.M.; Abraham, M.H.; Marcus, Y. \& Taft, R.W. Linear solvation energy relationships. 46. An improved equation for correlation and prediction of octanol/water partition coefficients of organic nonelectrolytes (Including strong hydrogen bond donor solutes). Journal of Physical Chemistry, (1998); 18 (92) 5244-5255.

[12] Taft, R.W. \& Kamlet, M.J. The solvatochromic comparison method. 2. The $\alpha$-scale of solvent hydrogen-bond donor (HBD) acidities. Journal of the American Chemical Society 1976; 10 (98) 2886-2894.

[13] Abraham, M. H \& Whiting, G.S. Hydrogen-bonding. Part 22. Characterization of soybean oil and prediction of activity coefficients in soybean oil from inverse gas chromatographic data. J. Am. Oil Chem. Soc., 1992; 69 1236-1238.

[14] Abraham, M.H.; Andonian-Hanftvan, J.; Osei-Owusu, J.P.; Sakellariou, P.; Urieta, J.S.; López, M.C. \& Fuchs, R. Hydrogen bonding. Part 25. The solvation properties of methylene iodide. J. Chem. Soc., Perkin Trans. II 1993; 3 299-304.

[15] Park, J.H. \& Carr, P.W. Interpretation of normal-phase solvent strength scales based on linear solvation energy relationships using the solvatochromic parameters $\pi^{*}, \alpha$ and $\beta$. J. Chromatogr. 1989; 465 (3) 123-136.

[16] Weckwerth, J.D.; Carr, P.W.; Vitha, M.F.; Nasehzadeh, A. A comparison of gashexadecane and gas-apolane partition coefficients Anal. Chem. 1998; 70 3712-3716.

[17] Abraham, M. H.; Whiting, G. S. \& Doherty R. M. Hydrogen Bonding. Part 13. A New Method for the Characterization of GLC Stationary Phases-The Lafford Data Set. J. Chem. Soc. PERKIN TRANS II 1990; 1451-1460.

[18] Abraham, M. H.; Whiting, G. S.; Doherty, R. M. \& Shuely, W. J. Hydrogen bonding XVI. A new solute solvation parameter, $\pi_{2}{ }^{\mathrm{H}}$, from gas chromatographic data. J. Chromatogr. $1991 ; 587$ 213-228.

[19] Abraham, M. H. Scales of Solute Hydrogen-bonding: Their construction and Application to Physicochemical and Biochemical Processes. Chem. Soc. Rev. 1993; 22 73-83.

[20] Platts, J.A.; Butina, D.; Abraham, M.H. \& Hersey, A. Estimation of molecular linear free energy relation descriptors using a group contribution approach. Journal of Chemical Information and Computer Sciences 1999; 39 835-845.

[21] Abraham, M.H. \& Platts, J.A. Hydrogen bond structural group constants. Journal of Organic Chemistry 2001; 66 3484-3491.

[22] Weckwerth, J.D. \& Carr, P.W. Study of Interactions in Supercritical Fluids and Supercritical Fluid Chromatography by Solvatochromic Linear Solvation Energy Relationships. Anal. Chem. 1998; 70 (7) 1404-1410. 
[23] Zhang, Y.; Dallas, A. J.; Carr, P. W. Critical comparison of gas hexadecane partitioncoefficients as measured with packed and open-tubular capillary columns J. Chromatogr. 1993; 638, 43-56.

[24] Li, Q.; Poole, C. F.; Kiridena, W.; Koziol, W.W. Chromatographic methods for the determination of the logL16 solute descriptorAnalyst, 2000; 125 2180-2188.

[25] Abraham, M.H.; Andonian-Haften, J.; My Du, C.; Osei-Owusu, J. P.; Sakellariou, P. Shuely, W.J.; Poole, C.F.; Poole, S.K. Comparison of uncorrected retention data on a capillary and a packed hexadecane column with corrected retention data on a packed squalane column J. Chromatogr. A 1994; 688 125-134.

[26] Defayes, G.; Fritz, D. F.; Görner, T.; Huber, G.; De Reyff, C.; Kovats, E. sz. J. Chromatogr., Organic solutes in paraffin solvents: Influence of the size of the solvent molecule on solution data. 1990; 500 139-184.

[27] Havelec, P.; Sevcik, J. G. K. Concept of additivity for a nonpolar solute-solvent criterion Log L(16) - Nonaromatic compounds J. Chromatogr. A 1994; 677 319-329.

[28] Havelec, P.; Sevcik, J. G. K. (1996). Extended additivity model of parameter log(L(16)) ,J. Phys. Chem. Ref. Data 1996; 25 1483-1493.

[29] Tranchant, J. Manuel pratique de chromatographie en phase gazeuse, Masson, Paris, 1995.

[30] Dallas, A.J.; Carr, P.W. Direct chromatographic comparison of the relative adsorption activity of various types of capillary transfer tubing Anal. Chim. Acta 1991; 251 83-93.

[31] Kersten, B.R. \& Poole C.F. Influence of concurrent retention mechanisms on the determination of stationary phase selectivity in gas chromatography J. Chromatogr. 1987; 399 1-31.

[32] Donovan, S.F. (1996). New method for estimating vapor pressure by the use of gas chromatography J. Chromatogr. A 1996; 749 123-129.

[33] Revelli, A.-L.; Mutelet, F. \& Jaubert, J.-N. Partition coefficients of organic compounds in new imidazolium based ionic liquids using inverse gas chromatography. Journal of Chromatography A 2009; 1216 (23) 4775-4786.

[34] Revelli, A.-L.; Mutetet, F.; Turmine, M.; Solimando, R. \& Jaubert, J.-N. Activity coefficients at infinite dilution of organic compounds in 1-butyl-3-methylimidazolium tetrafluoroborate using inverse gas chromatography. Journal of Chemical and Engineering Data 2009; 54 (1), 90-101.

[35] Mutelet, F., Jaubert, J.-N.; Rogalski, M.; Harmand, J.; Sindt, M. \& Mieloszynski, J.-L. Activity coefficients at infinite dilution of organic compounds in 1(meth)acryloyloxyalkyl-3-methylimidazolium bromide using inverse gas chromatography. Journal of Physical Chemistry B 2008; 112 (12) 3773-3785.

[36] Mutelet, F.; Jaubert, J.-N.; Rogalski, M.; Boukherissa, M. \& Dicko, A. Thermodynamic properties of mixtures containing ionic liquids: Activity coefficients at infinite dilution of organic compounds in 1-propyl boronic acid-3-alkylimidazolium bromide and 1propenyl-3-alkylimidazolium bromide using inverse gas chromatography. Journal of Chemical and Engineering Data, 2006; 51 (4) 1274-1279. 
[37] Mutelet, F. \& Jaubert, J.-N. Accurate measurements of thermodynamic properties of solutes in ionic liquids using inverse gas chromatography. Journal of Chromatography A 2006; 1102 (1-2), 256-267.

[38] Domańska, U. \& Marciniak, A. Activity coefficients at infinite dilution measurements for organic solutes and water in the ionic liquid triethylsulphonium bis(trifluoromethylsulfonyl)imide. Journal of Chemical Thermodynamics 2009; 41 (6) 754-758.

[39] Krummen, M.; Wasserscheid, P. \& Gmehling, J. Measurement of activity coefficients at infinite dilution in ionic liquids using the dilutor technique. J. Chem. Eng. Data 2002; 47 (6) 1411-1417.

[40] Poole, C.F. \& Poole, S.K. Extraction of organic compounds with room temperature ionic liquids. Journal of Chromatography A 2010; 1217 (16) 2268-2286.

[41] Abraham, M.H.; Zissimos, A.M.; Huddleston, J.G.; Willauer, H.D.; Rogers, R.D. \& Acree, W.E., Jr. Some novel liquid partitioning systems: Water-ionic liquids and aqueous biphasic systems. Ind. Eng. Chem. Res. 2003; 42 413-418.

[42] Acree, W.E., Jr. \& Abraham, M.H. The analysis of solvation in ionic liquids and organic solvents using the Abraham model linear free energy relationship. J. Chem. Technol. Biotechnol. 2006; 81 1441-1446.

[43] Sprunger, L.; Clark, M.; Acree, W.E., Jr. \& Abraham, M.H. Characterization of roomtemperature ionic liquids by the Abraham model with cation-specific and anion-specific equation coefficients. J. Chem. Inf. Model. 2007; 47, 1123-1129.

[44] Sprunger, L.M.; Proctor, A.; Acree, W.E., Jr. \& Abraham, M.H. LFER correlations for room temperature ionic liquids: Separation of equation coefficients into individual cation-specific and anion-specific contributions. Fluid Phase Equilib. 2008; 265 104-111.

[45] Sprunger, L.M.; Achi, S.S.; Acree Jr. W.E.; Abraham, M.H.; Leo, A.J. \& Hoekman, D. Correlation and prediction of solute transfer to chloroalkanes from both water and the gas phase. Fluid Phase Equilib. 2009; 281 144-162.

[46] Sprunger, L.M.; Gibbs, J.; Proctor, A.; Acree Jr., W.E.; Abraham, M.H.; Meng, Y.; Yao, C. \& Anderson, J.L. Linear free energy relationship correlations for room temperature ionic liquids: revised cation-specific and anion-specific equation coefficients for predictive applications covering a much larger area of chemical space. Ind. Eng. Chem. Res. 2009; 48 4145-4154.

[47] Mutelet, F; Ortega-Villa V.; Moise J.-C. Acree Jr., W.E. \& Baker, G.A. Prediction of Partition Coefficients of Organic Compounds in Ionic Liquids Using a TemperatureDependent Linear Solvation Energy Relationship with Parameters Calculated through a Group Contribution Method Journal of Chemical and Engineering Data 2011; 56 35983606. 